\title{
Ferramentas e desafios na gestão do processo editorial de revistas via Open Journal Systems: relato de caso
}

\author{
Paula Lorena Silva Melo \\ Pontifícia Universidade Católica do Paraná \\ paula.lorena@grupomarista.org.br \\ Marcelo Manduca \\ Pontifícia Universidade Católica do Paraná \\ manduca.marcelo@grupomarista.org.br \\ Elisama Nunes dos Santos \\ Pontifícia Universidade Católica do Paraná \\ elisama.santos@grupomarista.org.br
}

Como citar:

MELO, P. L. S.; MANDUCA, M.; SANTOS, E. N. Desafios na gestão do processo editorial de revistas via Open Journal Systems: relato de caso. In: ABEC MEETING, 2, 2018, São Paulo. Anais... São Paulo: Associação Brasileira de Editores Científicos, 2018. p. 1-5.

http://dx.doi.org/10.21452/abecmeeting.2018.186

\section{RESUMO}

Este trabalho tem como objetivo apresentar o sistema de gestão editorial de periódicos em uso na PUCPR, salientando os aprendizados feitos a partir da utilização do OJS (Open Journal Systems). Mostram-se aqui os desafios relacionados ao treinamento das equipes envolvidas no processo editorial - equipes das revistas e equipe de apoio às revistas, da Editora PUCPRESS - e à autonomização dessas equipes na busca de maximizar a eficácia da gestão dos periódicos via OJS. A quantidade de etapas envolvidas no processo editorial e suas particularidades, bem como a sazonalidade de algumas operações são vistas como os principais desafios a serem superados durante o uso do sistema. Para isso, propõe-se que sejam criados treinamentos específicos para os itens que geram mais dúvidas, que se invista mais tempo em formação continuada para as equipes e que tutoriais mais intuitivos e claros sejam disponibilizados aos usuários do sistema, em seus vários níveis.

Palavras-chave: Processo editorial. Gerenciamento de periódicos científicos. Open Journal Systems.

\section{ABSTRACT}

This article aims to present PUCPR's active journal's editorial management system, underlining the lessons learned from using OJS (Open Journal Systems). Challenges related to training the teams that are part of the editorial process - the journal's teams and the support team, under PUCPRESS - and making these teams autonomous are shown. The goal of tackling these challenges is to maximize the 
efficacy of managing journals through OJS. The amount of stages of the editorial process and their details, added to the seasonal character of some system operations are the main challenges that must be surpassed for better system usage. To achieve this, we propose the creation of specific coaching methods for the items that are more prone to generating doubts. We also believe that increased continued instruction time and more intuitive, clear tutorials, when available to the various users of the system, in their various levels, should be of valuable help.

Keywords: Editorial process. Scientific journals' management. Open Journal Systems.

\section{INTRODUÇÃO}

O Open Journal System (OJS) é uma plataforma profissional de publicação eletrônica disponibilizada pelo Public Knowledge Project (PKP), um projeto que tem como objetivo "entender e construir modos aprimorados de comunicação acadêmica que facilitem o acesso aberto, as publicações de alto nível e a capacitação e participação locais" (ALPERIN; STRANACK; GARNETT, 2016, tradução nossa). O sistema atualmente permite a gestão de periódicos e contempla praticamente todos os processos editoriais utilizados na produção de uma revista, da submissão à publicação.

Embora a ferramenta seja em geral suficiente para a gestão das revistas, foram desenvolvidos controles paralelos para contemplar alguns pontos particulares do processo que o OJS sozinho não abrange. A ampla maioria desses processos está na parte de produção, em que algumas etapas, especialmente na parte de revisão e leitura de provas, não são registradas de modo acessível e simples via sistema.

\section{O PROCESSO EDITORIAL}

Atualmente, o processo editorial envolve quatro macroprocessos: submissão, avaliação, edição e publicação. Destes processos, os dois primeiros são de responsabilidade da equipe da revista e os dois últimos, da equipe da Editora PUCPRESS, que opera os processos ou os acompanha quando são de terceiros. Dentro da área de edição, há ainda dois grandes processos: preparação de texto e edição de layout. O processo simplificado pode ser verificado, com seus responsáveis, no quadro abaixo:

QUADRO 1 - O PROCESSO EDITORIAL E SEUS RESPONSÁVEIS, POR ETAPAS

\begin{tabular}{|ll|}
\hline Etapa & Responsáveis \\
\hline Submissão & Equipe da revista \\
\hline Avaliação & Equipe da revista \\
\hline Edição (Preparação de texto e & Equipe PUCPRESS \\
Edição de layout) & Terceiros (contratados pela equipe da revista) \\
\hline Publicação & Equipe PUCPRESS \\
& Terceiros (contratados pela equipe da revista) \\
\hline
\end{tabular}

Fonte: Os autores (2018).

Em resumo, o artigo é submetido pelo autor, avaliado pelo editor da revista e, 
se julgado de acordo com a linha editorial, enviado à etapa de avaliação por pares. Nesta etapa, são designados os pareceristas que farão a avaliação cega do artigo. Uma vez aprovado pelos pareceristas, o artigo é designado para a edição de texto, onde passa por revisão e demais conferências textuais antes de ser devolvido ao autor para correções. Depois de voltar do autor, o artigo é designado a um editor de layout que fará a sua diagramação de acordo com os padrões da revista. Essa diagramação é conferida e eventuais ajustes de última hora são também aplicados nessa etapa, que pode acontecer mais de uma vez, a depender de vários fatores. A leitura de prova pelo autor e editor é designada a depender da revista e os artigos, após verificação final da equipe de revisão e preparação de texto, são publicados. Por ser um processo longo, requer-se aqui um controle bastante rigoroso para evitar falhas e problemas de prazo.

\section{AS FERRAMENTAS DE GESTÃO}

O sistema de gestão dos periódicos da PUCPR é o OJS. As etapas de submissão, avaliação, preparação de texto e publicação estão inteiras dentro do sistema. A etapa de edição de layout, porém, não ocorre inteira por ele. Na seção "Os desafios", explicaremos tal decisão. Atualmente, a designação do editor de layout acontece via sistema, mas as leituras de provas intermediárias não.

A gestão de mais de uma revista, com as etapas que são cumpridas no processo editorial aqui adotado, pressupõe ainda um controle mais sistemático, que possibilite a visão de todos os processos e o acompanhamento em detalhes do fluxo de cada artigo. Esse acompanhamento não é totalmente contemplado no OJS, de modo que foi desenvolvida uma planilha em Excel para suplementar dados do sistema e indicar as diversas fases de cada etapa, bem como acompanhar o versionamento dos arquivos em todas as etapas.

A planilha funciona com inserção manual e contempla as datas de início e final de cada procedimento, bem como status de eventuais pontos de atenção, incluindo a verificação de elementos (partes do texto, imagens, tabelas, referências e dados dos autores e do artigo), todas as etapas de layout (diagramação, cotejo e correção da diagramação), e o acompanhamento da pós-publicação (registro de DOI, envio de XML a indexadores, entre outros).

\section{OS DESAFIOS}

Um dos principais desafios da gestão do processo editorial é a necessidade de atualização e treinamento constantes das equipes envolvidas no processo. A falta de familiaridade com o sistema é um dos fatores que exigem formação contínua e adaptada a cada função. Atualmente, a equipe da Editora PUCPRESS disponibiliza-se para atendimento e treinamento dos editores e demais integrantes das equipes das revistas, dando suporte aos usuários do sistema. A maioria dos tutoriais e fóruns hoje disponíveis é altamente especializada em problemas não diretamente relacionados a processos editoriais (servidores, plugins e visual), temporalmente onerosos nas respostas devido à alta demanda de questionamentos ou em língua estrangeira, o que limita as opções das equipes quando em busca de atendimento rápido.

Entre os problemas mais relatados pelas equipes das revistas, a designação de pareceristas é uma das principais etapas que geram dúvidas. A ampla maioria das revistas trabalha com um banco de pareceristas cadastrado a partir de iniciativa do editor, mais que dos próprios pareceristas, então às vezes dados incompletos ou 
errados aparecem como entraves à designação e sua correção nem sempre é simples. Além disso, o versionamento, no sistema, especificamente, para que se envie o parecer cego também é um item que precisa de reforço periódico de treinamento, porque também é um ponto de dúvida razoavelmente frequente. Os atendimentos da equipe de apoio ao editor têm um dos focos nessa parte.

Durante a operação do sistema foi feito um primeiro teste em que todas as versões de layout eram inseridas no OJS. Assim, a primeira versão, ainda não lida ou corrigida pela equipe editorial, foi colocada no sistema, depois substituída por uma versão com correções, depois por uma versão corrigida, e o processo se repetiria até que a prova fosse dada como finalizada. Após isso, as leituras de provas seriam então disponibilizadas para autores e editores.

Esse planejamento, porém, não teve o resultado esperado, pois as provas ficaram abertas para leitura, o que ocasionou um influxo de comentários dos autores questionando itens que estavam já em processo de correção. A verificação desses comentários gerou retrabalho para a equipe editorial, que preferiu, em detrimento de manter o histórico das alterações nos arquivos registrado no próprio sistema, fazer o processo de correção de provas fora do sistema e submeter então apenas a última prova, que já estaria pronta a receber comentários de autores e editores, no sistema.

Além desses, também são enfrentados os desafios de instruir os autores sobre o sistema, uma função partilhada entre equipe das revistas e equipe PUCPRESS. O acompanhamento de todos os passos do processo de edição de texto é uma das partes mais delicadas dessa instrução, especialmente por esta ser majoritariamente remota. Dificuldades como não conseguir enviar o artigo corrigido via sistema ou esquecer de concluir a tarefa de correção são as mais comuns. Os atendimentos nesta área não são complexos, e sim instrucionais, mas exigem comunicação com o autor e instrução indireta, o que pode ocasionar certa lentidão em sua resolução.

Como se pode perceber, os desafios encontrados dizem respeito à falta de familiaridade não só com a ferramenta em si, mas com o modo como ela funciona, suas entradas e saídas processuais e a ordem de ocorrência desses processos. Há tutoriais disponíveis online e houve capacitação das equipes; entretanto, tais medidas não têm se mostrado suficientes para solucionar os desafios. Percebe-se ainda que parte do problema são justamente os diferentes níveis de usuário do sistema, pois alguns têm funções específicas, diferentes e por vezes sazonais que merecem maior atenção em treinamentos especializados e tutoriais mais práticos e intuitivos.

\section{CONSIDERAÇÕES FINAIS}

Acreditamos que o maior desafio em relação à gestão de periódicos pelo OJS é o desenvolvimento de autonomia de seus usuários. Como todo sistema de recente implementação, também o OJS atualmente passa por um período de adaptação de seus usuários e dos processos que devem agora contemplá-lo e suprir eventuais necessidades que ele não contemple.

O aprimoramento da equipe de apoio ao editor e o desenvolvimento de treinamentos mais focados para atender os desafios mais comuns, bem como de tutoriais sucintos e explicativos de etapas específicas, são alguns dos métodos que devem ser testados para catalisar a autonomização dos envolvidos no processo editorial. A instrução dos autores via site das revistas deve ser também esclarecida e um contato mais direto deve ser estabelecido para otimizar o tempo de resposta a demandas menores. 
No que diz respeito à gestão dos periódicos, o modelo atual, pautado no OJS e na planilha complementar, tem se mostrado suficiente e eficiente no controle do processo editorial e na manutenção da periodicidade e regularidade dos periódicos. Um dos pontos de melhoria nesse aspecto seria otimizar o preenchimento da planilha, que por enquanto é todo manual.

\section{REFERÊNCIAS}

ALPERIN, J. P.; S., K.; GARNETT, A. On the Peripheries of Scholarly Infrastructure: A look at the Journals Using Open Journal Systems. In: INTERNATIONAL CONFERENCE ON SCIENCE AND TECHNOLOGY INDICATORS, 21., 2016, Valência. Proceedings... Valência: [s. n.], 2016. Disponível em: <http://summit.sfu.ca/ item/16763 >. Acesso em: 23 maio 2018. 